\title{
A RESIDÊNCIA PEDAGÓGICA NA PERSPECTIVA DA FORMAÇÃO INVENTIVA DE PROFESSORES DE MATEMÁTICA
}

The Pedagogical Residence in the perspective of the Inventive Training of Mathematics Teachers

La residencia pedagógica en la perspectiva de la formación inventiva de los profesores de matemáticas

\author{
Hevellyn Tays Lima da Silva* ${ }^{*}$, Deive Barbosa Alves ${ }^{1}$ \\ ${ }^{1}$ Residência Pedagógica, Licenciatura em Matemática, UFT, Araguaína, Brasil.
}

*Correspondência: Licenciatura em Matemática, UFT, Av. Paraguai (esquina com a Rua

Uxiramas), s/n Setor - Bairro da Cimba, Araguaína, Tocantins, Brasil. CEP:77824-838. e-mail

hevellyntays@gmail.com.

Artigo recebido em 03/04/2020 aprovado em 09/04/2020 publicado em 16/04/2020.

\section{INTRODUÇÃO}

Este artigo visa discutir ações desenvolvidas no Programa de Residência Pedagógica (RP), da Universidade Federal do Tocantins (UFT), as quais promoveram movimentos educacionais específicos, com o objetivo de fornecer conhecimento teórico e prático no contexto de uma política de formação inventiva de professores de matemática e suas possíveis contribuições para os residentes inserido no programa em questão.

Deste modo ao olhar o desenvolvimento das atividades da RP por este ângulo, os residentes aprendem pela invenção de si e do mundo, tivemos como norte a seguinte indagação: como o Programa Residência Pedagógica pôde contribuir para a formação de um profissional capaz de desenvolver ações que façam a diferença nas atividades desenvolvidas em sala de aula?

Para responder tal questionamento buscamos explicar os fatos por análises micropolíticas, pois elas “[...] apontam para experiências concretas, em que se estabelecem os conflitos entre o vivido e os padrões de desempenho formulados a partir da lógica geral instituída" (DIAS 2011, p. 273 ).

\section{REFERENCIAL TEÓRICO}

Quando pensamos no termo "invenção" podemos associá-lo a criatividade, Silva (2019), mas a invenção não se limita apenas na resolução do problema, e sim em encontrar pontos que contrapõe sua resolução, cria-se, na invenção, algo autoral. Desse ponto de vista percebemos

[...] que as ações e práticas inventivas não estão subjugadas às determinações invariantes e previsíveis de leis, regras ou parâmetros cristalizados. As ações e práticas inventivas não podem ser acessadas via algum tipo de teoria da invenção, o que as tornariam previsíveis, contrapondo-se a abertura para o imprevisível do qual emergem novidades que constituem ações e práticas inventivas (SILVA, 2019, p. 32).

Contudo ações e práticas inventivas não são um convite ao consumo. São possibilidades de se produzir algo que dure e isso não é oposto ao criar, pois é produzir o que dure nos afetos daquilo que foi produzido, é um durar no sentido da produção da subjetividade. Nesse se destaca a não passividade nos desenvolvimentos das atividades, uma vez que 
[...] a invenção se alimenta da ação, do fazer, do agir que se configura a partir das misturas que ocorrem no coletivo e causam estranhamentos quando somos afetados pelo que é diferente, inédito, [...] (SILVA, 2019, p. 33).

Observa-se uma comunhão entre teoria e prática na invenção, a qual possibilita utilizar-se do cotidiano, do ato de formular questões, de inventar formas de resolução, o que pode possibilitar o aluno um maior conhecimento de sua realidade. Comunhão visualizada pela micropolítica, compreendida como uma experimentação ativa, em que se estabelece a RP produzida e reconhecida por ela. Isso "significa dar ênfase às análises das circunstâncias em que nós produzimos, aos modos de subjetivação, a uma multiplicidade de formas e de forças" (DIAS, 2011, p. 273).

\section{METODOLOGIAS E MATERIAIS}

Pela natureza dos dados produzidos nossa investigação se enquadra na abordagem qualitativa, a qual

[...] assume os princípios da epistemologia apriorístico, e se situa, na intenção de descobrir aspectos novos na sua relação, com os sujeitos investigados, os quais devem construir de forma conceitual por meio de um processo permanente de formulação de hipóteses que vão definindo os diferentes eixos de construção de informação ao longo da investigação (REY, 2003, p. 269).

Essa abordagem se entrelaça, em nossa compreensão, é o caminho para construção interpretativa da micropolítica da formação inventiva do professor de matemática, pois ambas se fundamentam na experiência presente, dando ênfase aos modos de subjetivação.

Este relato de pesquisa foca na experiência de uma residente que ministrou aulas para um grupo de 14 alunos, em turma de Educação de Jovens e Adultos
(EJA), estudavam o primeiro do ensino médio, no Instituto Federal de Educação, Ciência e Tecnologia do Tocantins (IFTO).

Os dados foram produzidos a partir das produções dos alunos do EJA, dos registros nos cadernos de campo da residente e interpretados pela análise qualitativa do conteúdo.

\section{RESULTADOS E DISCUSSÃO}

Os relatos apontam para duas discussões, uma que fundamenta a formação inventiva de professores, a experiência presente, e a outra na ideia de conflito, esse no sentido de deslocamento de forma e forças. Iniciemos pela primeira.

sabe professora eu faço bolo, para vender, eu sei que eu uso muita matemática, nas medidas, para fazer o bolo, e na venda também! mas lá é fácil, essa matemática que ensina aqui é muito difícil, e também não dá para usar. (aluno 2) (diário de campo de um residente sobre um aluno do EJA).

$\mathrm{Na}$ prática da formação inventiva de professores, vemos que seu fundamento é a experiência presente. Experiência no sentido de Larrosa (2004, p. 162), na qual ela é “[...] aquilo que nos passa, ou nos toca, ou nos acontece, e ao nos passar nos forma e nos transforma. Somente o sujeito da experiência está, portanto, aberto a sua própria transformação". Essa experiência do presente que nos forma e transforma, segundo Dias (2011) é

[...] mais um refinamento da percepção e da atenção do que um apelo ao saber acumulado ou à memória. É, acima de tudo, uma questão de aprendizado da sensibilidade ao campo de forças e às políticas que o atravessam. Trata-se de um cultivo da atenção concentrada e aberta à experiência de problematização (DIAS, 2011, p. 273).

Percepção que fez a professora em formação, a residente, inventar uma pequena feira de compra e 
venda de produtos, contudo esse deslocamento para o campo da prática que a percepção permitiu, causa na experimentação ativa conflitos dialéticos

Eu sou mais velha, então eu sou mais lenta para aprender essas coisas, eu gosto quando vocês trazem essas atividades que é mais diferente, a gente aprende e nem ver, (aluno 3) (diário de campo de um residente sobre um aluno do EJA).

Eu não gosto dessas coisas diferentes, eu gosto de chegar sentar e escrever as atividades e ir embora, essas atividades são muito difíceis, tem que pensar muito para responder, (aluno 5) (diário de campo de um residente sobre um aluno do EJA).

Esses dizeres apontam para conflitos do deslocamento entre o vivido e os padrões instituída, que imprimem no futuro professor a "marca" da pluralidade,

O mestre pluralista não possui a verdade e não admite que alguém possa possuí-la, pois a mesma é para cada um o sentido da sua própria situação. Não se recusa a examinar, a inovar, a arriscar e a experimentar qualquer proposta, pois o seu primeiro compromisso racional deveria estar orientado a favor da qualidade da aprendizagem e do saber dos seus alunos, não podendo os mesmos ser imaginados desconciliados e deixando de preservar atitudes libertadoras, de vida completa e gratificante, (LERNER e SADOVSKY, 1996, p.254).

Desse ponto de vista a experimentação ativa apresentada pela residente estabelece a exploração de outras epistemologias metodológicas, caminhando para as ideias pluralismo metodológico em que

(...) uma pessoa que tenta resolver um problema, seja em ciência ou outro lugar qualquer, deve ter liberdade completa e não pode ser restringido por nenhuma demanda ou normas, ainda que pareçam plausíveis ao lógico ou ao filosófico que as tenham idealizado em seus estudos privados. (FEYERABEND, 1978, p.117).

Essas considerações nos mostram que, nestas perspectivas, a verdade por ser alcança por diversas formas e que ao utilizar uma metodologia pluralista apresentará uma melhor desenvoltura no decorrer das atividades docentes, mas boa parte do tempo esse profissional se verá em conflito com os sujeitos que os padrões instituídos.

\section{CONSIDERAÇÕES FINAIS}

Nossos resultados e discussões mostram que o RP pôde contribuir para a formação de um profissional que busca pela pluralidade metodológica, observando as experiências concretas e presentes. E também ampliando e refinando a percepção da subjetividade da profissão docente, bem como cultivando a atenção concentrada e aberta à experiência de problematização dos fatos vividos pelos estudantes. O que constitui a formação inventiva de professores em um território em movimento de conhecimento vivo e incorporado, (DIAS, 2011).

Todos os autores declararam não haver qualquer potencial conflito de interesses referente a este artigo.

\section{REFERÊNCIA}

DIAS, Rosimeri de Oliveira. Pesquisa-intervenção, cartografia e estágio supervisionado na formação de professores. Fractal: Revista de Psicologia, Niterói, v. 23, n. 2, p.269-290, 01 mar. 2011. Disponível em: encurtador.com.br/afBR9. Acesso em: 02 fev. 2020.

FEYERABEND, Paul Karl. Science in a Free Society. London: NLB, 1978.

LARROSA, Jorge. Linguagem e educação depois de Babel. 2. ed. Belo Horizonte: Autêntica Editora, 2004. 360 p. (Educação: Experiência e Sentido). (p. 162), Edição do Kindle.

LERNER, D.; SADOVSKY, P. O sistema de numeração: um problema didático. In: PARRA, C. SAIZ, I. (Org.). Didática da matemática: reflexões psicopedagógicas. Porto Alegre: Ed. Artmed. 1996. p. 73-155.

REY, Fernando Luis González. Sujeito e Subjetividade: uma aproximação histórico-cultural. Tradução de Raquel Souza Lobo Guzzo. São Paulo: Pioneira Thomson Learning, 2003. 
SILVA, Marcos Roberto da. Experiência com Robótica Educacional no Estágio-docência: uma perspectiva inventiva para formação inicial dos professores de matemática. 2020. 301 f. Tese (Doutorado) - Curso de Programa de Pós-graduação em Educação, Educação, Universidade Federal de Uberlândia, Uberlândia, 2020. Cap. 5. Disponível em: encurtador.com.br/dNRU6. Acesso em: 05 mar. 2020. 